\title{
VEGA-SCIENCE SERVICES FOR MONITORING THE IMPACT OF TECHNOGENIC WASTE AND DUMPS SOURCES ON ENVIRONMENT
}

\author{
V. P. Savorskiy ${ }^{1,2,{ }^{*}, \text { E. A. Loupian }}{ }^{1}$, O. Yu. Panova ${ }^{1,2}$, A. M. Konstantinova ${ }^{1}$, D. M. Ermakov ${ }^{2}$, I. V. Balashov ${ }^{1}$ \\ ${ }^{1}$ Space Research Institute of the Russian Academy of Sciences (IKI RAS), 117997 Moscow, Russia - evgeny@d902.iki.rssi.ru \\ ${ }^{2}$ Kotelnikov Institute of Radioengineering and Electronics of the Russian Academy of Sciences, Fryazino Department (FIRE RAS), \\ 141190 Fryazino, Moscow region, Russia - savor@inbox.ru
}

Commission III, WG III/7

KEY WORDS: Earth Satellite Observations, Information Technology, Forest resources, Technogenic Waste and Dumps Sources

\begin{abstract}
:
The impact of hazardous waste on people and the environment from agricultural, industrial, military and mining activities form one of the most significant global environmental challenges. These wastes often include heavy metals, acid precipitates (sulfur oxide solutions), hydrocarbons, and other organic chemicals. Environmental impact of such technogenic waste and dumps sources (TWDS) is widely reflected in vegetation cover changes, which can be easily detected by satellite instruments. But application of satellite data for TWDS monitoring requires appropriate information tools. At presented work, the authors conducted the development of the design and implementation of these tools within frames VEGA-Science services (http://sci-vega.ru/eng/) in order to provide analysis of longterm variability of the vegetation cover state caused by the influence of TWDS. The result of the work was included in automated system for remote monitoring of vegetation cover (SRMV) of VEGA-Science system.
\end{abstract}

\section{INTRODUCTION}

The impact of hazardous waste on people and environment from mining is one of the most significant global environmental challenges. Influence of hazardous waste on environment is currently compounded due to an increase in the intensity of mining, with the development of less rich deposits and the transition to open pit mining. An open mining is due to its significant reduction in price comparable to underground one. But at the same time, open pits completely destroy the surrounding areas of the landscape, forming an open vast crater and various technogenic waste and dumps sources (TWDS). These sources often include heavy metals, acid precipitation (solutions of sulphur oxides), hydrocarbons and other organic chemicals. The development of methods for monitoring the state of vegetation, which reveals environment changes due to impact of TWDS is the main goal of the work.

The paper (Savorskiy et al., 2019) gives an analytical review describing the mechanisms of influence of typical harmful TWDS on the vegetation covers and proposes methods and approaches that allow identifying changes in the vegetation cover caused by the influence of TWDS. That work results in the statement of proposals for making up the comprehensive list of parameters for forest state control based on satellite observations, including the use of spectral indices for these purposes. The obtained results allowed substantiating the use of the funds and resources of IKI-Monitoring (Loupian et al., 2019) as a platform for the development of tools to control the TWDS the impact.

The presented paper contains the results of the paper (Savorskiy et al., 2019) continuation in developing information services necessary for implementation remote sensing control of TWDS impact on forestland environment. Namely, the main objective of the work is the creation and the upgrade of the information tools of the VEGA-Science system (http://sci-vega.ru/eng/) to be able to analyse of the changes in state of the vegetation cover for monitoring TWDS impact. To achieve this goal, proposals for the modernization and development of the VEGA-Science services have been defined to provide users with capacities to analyse long-term variability of the vegetation cover caused by the influence of TWDS.

The main methodological approach in the work is the objectoriented design method, based on the clarification of user requirements and the development of software services that meet these target requirements.

\section{MONITORING OF HOMOGENEOUS AREAS OF VEGETATION SUBJECT TO VARIOUS LEVELS OF TWDS IMPACT}

Anthropogenic impact on environment as a result of agricultural, industrial, military, and mining activities forms significant environmental challenges, up to global. Traditional field and laboratory methods for detecting and monitoring the effects of such exposure include, as a rule, costly and time-consuming exploration works. A useful alternative to detect anthropogenic impact and eliminate its effect is the aerospace monitoring methods. Multispectral observation systems installed on satellites are currently successfully used for spectral and morphological analysis of vegetation disturbances, morover, hyperspectral systems make it possible to determine the composition of pollutants by their spectral features (Sloneker et al., 2010).

Vegetation, which grows in anthropogenically effected territories, is usually characterized by a pronounced intraspecific differentiation in terms of resistance to pollutants as shown in (Kositsin, Alekseeva-Popova, 1983; Krupa et al., 1990; Schweizer, Arndt, 1990). An analysis of the effects of pollutants on the physiological processes of plants allows us to identify the main mechanisms of this effect (see, for example, a review (Titov et al., 2014)), including 1) growth, 2) development, 3) photosynthesis, 4) respiration 5) water exchange. These influence factors form the main signs of disturbance of the vegetation cover for a given plant species.

\footnotetext{
* Corresponding author: savor@inbox.ru
} 
The detection of signs of disturbance of vegetation according to satellite remote sensing data is proved to be reliable, as shown by the results of the studies (Van der Meer, de Long, 2006; Wang et al., 2008; Gornyy et al., 2011, 2013; Tolpin et al., 2014; Kalabin et al., 2016; Kritsuk et al., 2016; Savorskiy et al., 2018; Zakharov, 2018). However, in the general case, these signs are difficult to isolate against the background of seasonal variations in the spectral characteristics of the plant cover caused by the natural interannual temperature-humidity variability of plant growth and development conditions. In this regard, the aim of this work is to develop a new methodological approach that provides the detection and monitoring of the vegetation disturbances caused by anthropogenic activity against the background of natural seasonal and interannual variability of vegetation parameters with the use of remote sensing data.

The degree and severity of TWDS impact substantially depends on the type of vegetation cover and on the weather and climatic conditions in which this effect occurs (see (Savorskiy et al., 2019) and references therein). In particular, for forest cover, TWDS impact depends on the biological characteristics of the main tree species that grow on the observer site, their age status and quality class. Important characteristics of the vegetation areas where the impact of TWDS is being assessed are also their spatial uniformity and connectivity.

The main measure to increase the reliability of detecting signs of forest disturbance in the proposed approach is to select a reference vegetation site that is identical in its taxonomic characteristics to vegetation in a controlled area, growing in similar weather and climate conditions and not exposed (in contrast to the controlled area) to a harmful agent. This condition is satisfied when choosing the reference section upstream of the main atmospheric transfer, i.e. up along the prevailing wind directions from the TWDS, and higher in the river flow relative to the source of pollution. The TWDS impact is detected by comparing the forest state parameters or special spectral indices describing forest state of controlled forest site (underwent by TWDS impact) and reference site (clean of TWDS impact).

For these purposes, we need to choose homogeneous forest sites, which we could observe for long time, up to 10-20 years. The possibility of identifying and long-term satellite monitoring of forest cover sites that are homogeneous in taxonomy and weather and climatic conditions according to satellite observations is confirmed by a number of works of the IKI RAS (Bartalev et al., 2016). An important result of these studies is the justification of the possibility of generating long-term homogeneous series of experimental satellite monitoring data for sites with the same or similar taxonomy at the start of observation period. Such an opportunity provides the identification of long-term trends of the difference characteristics of sites, one of which is subject to more intense TWDS impact than the other ones. For example, in the case, they are at different distances and the same azimuth from the TWDS, or even at an equal distance, up and down along the prevailing wind directions from the TWDS. Various approaches can be used to select sites with different levels of pollution, including those related to the identification of clean and contaminated zones in TWDS areas according to accompanying and independent remote observations. For example, as a result of analysis of the state of the snow cover and its dynamics in winter and spring according to satellite monitoring.

When choosing control sites, it is necessary, in particular, to take into account that temperature and humidity conditions have, along with temporal, significant spatial variability. This leads to significant spatial variations in the conditions of growth and development of vegetation, which in turn can mask and / or distort the influence of TWDS. Therefore, when identifying homogeneous areas of vegetation along with taxonomic, it is necessary to ensure the proximity of control sites according to their weather and climatic conditions, primarily according to synoptic, seasonal and annual indicators of temperature and humidity characteristics of these sites. For this, it is necessary to use long-term series of temperature and humidity parameters of selected sections of the forest territory.

It is important to note that in order to reliably establish the effect of TWDS on vegetation, it is necessary to provide long-term monitoring, since the influence of TWDS in a significant number of cases depends on the cumulative effect of the results of the influence of harmful substances on the tested areas of vegetation cover. Therefore, to study the impact of TWDS on the environment, it is desirable to monitor long-lived plant communities, which include, for example, forests. To conduct such studies, it is necessary to obtain and analyze long-term series of satellite observations. Such an analysis should provide a decrease in the impact on the obtained estimates of factors such as significant intra-seasonal and interannual variability of the temperature and humidity conditions of plant growth and identify significant changes associated with the long-term influence of TWDS on the state of the vegetation cover of the regions in which they are located

In order to improve reliability of change detection, the developed method assumes also estimations of disturbance by signs of deviations in intensity of photosynthesis, respiration and water metabolism (Jorgensen, Svirezhev, 2004; Gornyy et al., 2010), to evaluate their average seasonal values. As well, parameters of their seasonal phenological profiles (Savorskiy et al., 2018) and their multiseasonal cumulative values, in particular, for assessing the total biomass growth of the observed vegetation cover (Zakharov et al., 2018), are estimated in order to increase reliability of TWDS impact detection.

When implementing the developed approach, existing resources of the VEGA satellite services (Tolpin et al., 2014; Loupian et al., 2015; Kashnitsky et al., 2016) were used to explore homogeneous areas of vegetation land cover, especially forestlands. In order to increase the efficiency of the system in the monitoring of homogeneous forest areas underwent by TWDS impact, the VEGA-Science satellite services have been extended by:

1) the database of objects with potential TWDS impact (quarries, dumps, tailings);

2) the database of referenced forest plots unexposed by TWDS with species composition, which has maximum sensitivity to pollutants;

3) the database of controlled area forest plots exposed by TWDS with species composition, which has maximum sensitivity to pollutants;

4) the collection of long-term satellite observations of controlled and reference sites;

5) automated tools for monitoring the growth, development, photosynthesis, respiration, and water metabolism of vegetation which are possible to retrieve from remote data.

\section{POTENTIAL POSSIBILITIES OF REMOTE IDENTIFICATION OF THE MAIN TYPES OF NEGATIVE TWDS IMPACT ON VEGETATION COVER}

This section briefly analyzes the possibilities of using remote sensing data to identify the processes with the negative TWDS impact on vegetation (primarily forest) cover.

Identification of plant growth disorders. As the main tool for satellite detection of plant growth disorders following work (Kalabin et al., 2010; 2013; 2014; 2016; 2018; Kritsuk et al., 2013), which stated appropriateness of NDVI (Normalized Difference Vegetation Index) for TWDS impact detection, we propose using NDVI and similar indices, which represent the state of the vegetation cover (NDVI, PVI (Perpendicular 
Vegetation Index), AVFI 1600 (Aerosol Free Vegetation Index 1600), LAI (Leaf Area Index), DWSI5 (Disease Water Stress Index 5), EVI (Enhanced Vegetation Index), NDNI (Normalized Difference Nitrogen Index), OSAVI (Optimized Soil Adjusted Vegetation Index), PEI (Potassium Emission Index), TCARI (Transformed Chlorophyll Absorbtion Ratio Index) (Savorskiy et al., 2016). These indices should be estimated both for controlled test sites that are subject to TWDS impact and for reference sites that are not influenced by TWDS impact in similar weather and climate conditions. It should be stated that reliable detection of disturbances is possible only with the use of long-term series of observations, since it cannot be ruled out that a change in the vegetation cover during short-period changes may turn out to be insignificant, so such change could be undetectable by satellite remote sensing means. At the same time, long-term observations allow to increase the stability of the observed spectral characteristics of the forest, and, consequently, the accuracy of detecting disturbances due to the cumulative effect caused by TWDS impact. An analysis of differences in the behavior of indices in test areas that are subject to and not subject to TWDS impact can allow minimizing factors not related to anthropogenic impact, but caused, in particular, by synoptic, seasonal and interannual variability of temperature and humidity conditions of plant development, and thereby highlight the manifestation the TWDS impact. It should be noted that the degree of impaired growth depends on the type of vegetation. Therefore, with the constant suppression of some forest species, others may not experience any changes. As a result of the long-term TWDS impact, it is likely that significant changes in the species composition of the vegetation cover at controlled sites become possible.

Identification of developmental disorders. Involvement of NDVI or similar spectral indices is also useful for detecting plant growth disorders. However, in this case, the analysis should focus on identifying differences in the seasonal profiles of the indices (Savorsky et al., 2018). For this case, an analysis should compare index differences for homogeneous plots exposed to TWDS impact and for reference plots not affected by TWDS in the same weather and climate conditions, in order to detect possible changes in the seasonal phenological cycle, which will indicate inhibition and, ultimately, death of vegetation sensitive to the TWDS impact.

Identification of disturbances in the photosynthesis processes. Identification of disturbances in the photosynthetic apparatus is one of the most sophisticated characteristics from the point of view of satellite observations. However, in this case as well, it is possible to indirectly characterize the intensity of photosynthesis by a change in indicators characterizing the content of chlorophyll, in particular, by the spectral index of chlorophyll TCARI (Savorsky et al., 2016).

Identification of respiratory disorders and water metabolism disorders of plants. To identify disturbance of the forest cover associated with problems of respiration and water metabolism of plants, it is advisable to apply the methodological approach described in (Gornyy et al., 2010, 2011, 2013, 2019). This method is based on results of (Jorgensen, Svirezhev, 2004) showed that the rate of evaporation of moisture from the surface of an ecosystem is a measure of the response of an ecological system to external influences. These results allowed to develop the thermodynamic index of ecosystem disturbance (TIED):

$$
\text { TIED }=\frac{E x_{C}^{0}-E x_{C}}{E x_{C}^{0}}
$$

where $E x_{C}^{0}$ and $E x_{C}, \mathrm{~W} / \mathrm{m}^{2}$ are exergy (Jorgensen, Svirezhev, 2004) of the absorbed solar radiation spent on carbon deposition of the background (healthy) and investigated disturbed ecological system, respectively. In our terms, they are the reference plots not affected by TWDS and the plots exposed to TWDS impact, respectively. The exergy of the solar radiation absorbed by the surrounding ecosystem spent on carbon deposition is directly proportional to the amount of moisture evaporated by ecological system (Jorgensen and Svirezhev, 2004; Gornyy et al., 2010, 2011):

$$
E x_{C}=3,66 \times E,
$$

where $E$ is the specific average daily rate of moisture evaporation from the surface of the ecological system, $\mathrm{kg} / \mathrm{m}^{2} \mathrm{~s}$.

Table 1 provides a brief summary of the possibility of using various characteristics and analysis methods to identify the main types of negative impact of TWDS on the vegetation cover.

\begin{tabular}{|l|l|l|}
\hline Task & $\begin{array}{l}\text { Characteristics } \\
\text { retrieved from } \\
\text { remote sensing } \\
\text { data }\end{array}$ & $\begin{array}{l}\text { Main directions of } \\
\text { the analysis of } \\
\text { series of } \\
\text { observations }\end{array}$ \\
\hline $\begin{array}{l}\text { Identification of } \\
\text { plant growth } \\
\text { disorders }\end{array}$ & $\begin{array}{l}\text { NDVI, PVI, } \\
\text { AFVI1600, LAI }\end{array}$ & $\begin{array}{l}\text { Perennial analysis } \\
\text { trends. } \\
\text { Comparative } \\
\text { analysis of the } \\
\text { development of } \\
\text { contaminated and } \\
\text { unpolluted test sites }\end{array}$ \\
\hline $\begin{array}{l}\text { Identification of } \\
\text { developmental } \\
\text { disorders }\end{array}$ & $\begin{array}{l}\text { NDVI, PVI, } \\
\text { AVFI1600, } \\
\text { LAI, DWSI5, } \\
\text { EVI , NDNI, } \\
\text { OSAVI, PEI, } \\
\text { TCARI }\end{array}$ & $\begin{array}{l}\text { Perennial analysis } \\
\text { trends. } \\
\text { Interannual } \\
\text { comparative } \\
\text { analysis of the } \\
\text { development of } \\
\text { contaminated and } \\
\text { unpolluted test sites }\end{array}$ \\
\hline $\begin{array}{l}\text { Identification of } \\
\text { violations of } \\
\text { photosynthesis } \\
\text { processes }\end{array}$ & TCARI & $\begin{array}{l}\text { Comparative } \\
\text { analysis of the } \\
\text { development of } \\
\text { contaminated and } \\
\text { unpolluted test sites }\end{array}$ \\
\hline $\begin{array}{l}\text { Identification of } \\
\text { respiratory } \\
\text { disorders of plants }\end{array}$ & TIED & $\begin{array}{l}\text { Comparative } \\
\text { analysis of the } \\
\text { development of } \\
\text { contaminated and } \\
\text { unpolluted test sites }\end{array}$ \\
\hline disorders of plants & E (Eq.2) & $\begin{array}{l}\text { Comparative } \\
\text { analysis of the } \\
\text { development of } \\
\text { contaminated and } \\
\text { unpolluted test sites }\end{array}$ \\
\hline
\end{tabular}

Table 1. Possibilities of identifying the main types of negative impact of TWDS on the vegetation cover

\section{OBSERVATIONAL AND AUXILIARY DATA REQUIRED FOR THE ASSESSMENT OF THE TWDS IMPACT ON FOREST COVER}

As it has been preliminarily discussed in Sec.2, the peculiarity of the algorithms for detecting the impact of TWDS is the need to consistently, i.e. in a wide range of meteorological parameters, detect the disturbance of vegetation against the background of strong interannual, seasonal and intra-seasonal variability. This necessity is determined by the peculiarities of temperature and humidity conditions, which develop differently in each of the annual cycles, which leads to significant differences in the phenological cycles of plant development. Therefore, the detection of disturbance caused by TWDS, involves the use of such methods of monitoring the state of vegetation, which are 
robust to changes in temperature and humidity conditions. It is necessary in order to ensure long-term monitoring of control areas of forest cover for 10-20 years for at least one of the types of disturbance described in the paper (Savorskiy et al., 2019), which influence plants 1) growth, 2) development, 3) photosynthesis, 4) respiration, 5) water exchange.

The need to detect the influence of TWDS at significantly different temperature and humidity observation conditions form the following number of requirements for the list of the source and auxiliary data that ensure stable operation of the algorithms for detecting forest canopy disturbance caused by TWDS:

1) TWDS description database (coordinates, type, formation period, polluting factor),

2) the database of the forest plots (allotments) having close characteristics and taxonomy (main breeds, stock, quality class) to the ones in the areas of TWDS,

3) the database for search and selection of forest areas (allotments) having similar weather and climatic characteristics (temperature, humidity, soil moisture, wind speed and direction) to the ones in the areas with TWDS impact,

4) medium and high spatial resolution historical satellite observations data archive for selected control and reference forest areas,

5) medium and high spatial resolution real time satellite observations data archive for selected forest areas.

\section{SERVICES REQUIRED FOR THE DETECTION OF THE TWDS IMPACT ON VEGETATION COVER}

As follows from the analysis, in order to automatically detect the TWDS impact on forest vegetation cover, an automated system for remote monitoring of vegetation cover (SRMV) in the TWDS areas should be launched, being able to provide the following capabilities:

1) service for managing the list of the forest sites (allocations) having taxonomy (basic breeds, stock, quality class) similar to ones in the areas of TWDS,

2) service for managing the list of forest areas (allotments) having similar weather and climatic characteristics (temperature, humidity, soil moisture, wind speed and direction) to ones in the areas of TWDS,

3) service for managing the pairs ("controlled forest plot" "reference forest plot"), which is based on the similarity of pair constituent in taxonomy and weather and climatic conditions,

4) service enabling the estimations of spectral indices, which characterize the state of the vegetation cover, including NDVI, AVFI1600, DWSI5, EVI, NDNI, OSAVI, PEI, TCARI (see the paper (Savorskiy et al., 2019) and references therein) and TIED (Gornyy et al., 2013; Gornyy et al., 2010), based on medium and high spatial resolution to historical and current satellite observations for pairs ("controlled forest plot" - "reference forest plot"),

5) service enabling the estimations of difference in spectral indices for the pairs of the sites ("controlled forest plot" "reference forest plot") having the same weather and climatic conditions and having the same taxonomy at the beginning of monitoring,

6) service enabling the retrieval of index dataset, which describes phenological seasonal cycles for pairs of sites ("controlled forest plot" - "reference forest plot") having the same taxonomy at the beginning of monitoring,

7) service for detection and monitoring of long-term cumulative trends of spectral index differences for pairs ("controlled forest plot" - "reference forest plot"),
8) service for distinguishability assessment (statistical measure of distinguishability) for pairs ("controlled forest plot" "reference forest plot") having the same weather and climatic conditions, in particular, using the Jeffries-Matsushita distance (Richards, Jia, 2006).

All the above algorithms and services should be provided with remote access user web interfaces (Loupian et al., 2012).

\section{CAPABILITIES OF THE "IKI-MONITORING" CENTER FOR COLLECTIVE USE FOR SOLVING THE PROBLEMS OF TWDS MONITORING}

The requirements listed in sections 4,5 are substantially satisfied by information tools developed and implemented in the information system of the "IKI-Monitoring" Center for Collective Use (CCU) (http://ckp.geosmis.ru/). So, the VEGAScience services and tools can be used as the prototypes during the development of tools for remote access to the remote forest monitoring data in order to detect forest disturbance due to the TWDS impact. They provide:

1) accurate geographical reference of the observed satellite monitoring data and derived data products, including spectral indices,

2) estimation of statistical parameters of the observed satellite monitoring data and derived data products, including spectral indices for selected forest plots,

3) preparation of spectral index maps, including ones, which could be updated by users in the online mode,

4) availability of charting seasonal profiles of observed satellite monitoring data and derived data products for selected forest plots.

The availability of such prototype tools ensured the rapid successful implementation of the TWDS SRMV as a unit of the VEGA-Science system. This is also facilitated by the operation of the "IKI-Monitoring" CCU, which includes VEGA-Science systems, information resources of long-term satellite monitoring and related information.

\section{IMPLEMENTATION OF SRMV AS A SUBSYSTEM OF THE "IKI-MONITORING" CCU}

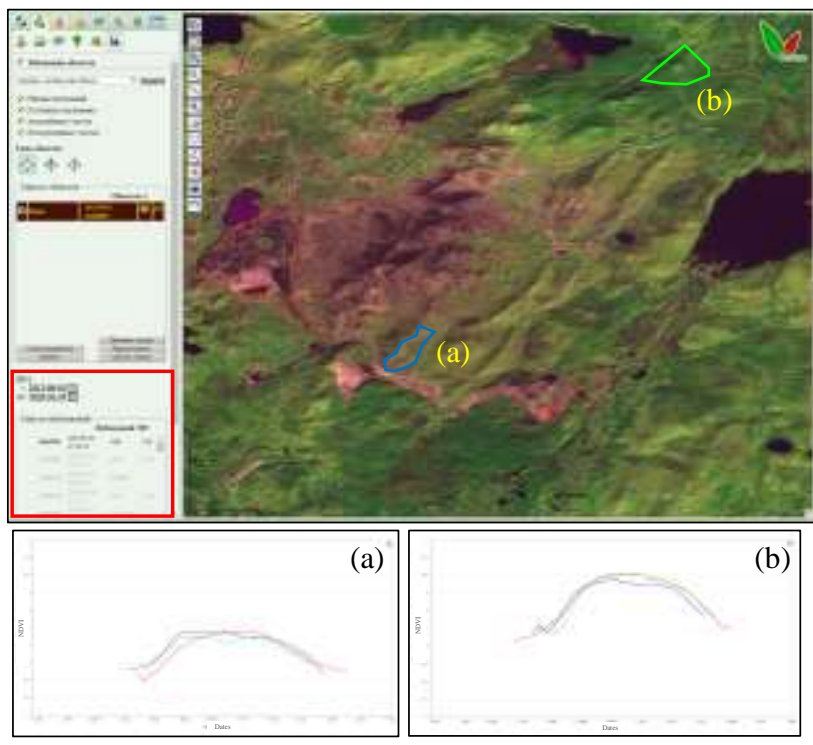

Figure 1. Interface of the specialized unit for remote monitoring of forest areas influenced by TWDS. Example of forest state analysis around the "Karabashmed" TWDS (Chelyabinsk region) including seasonal profile and parameter panels 
The software prototype of TWDS SRMV for remote monitoring of the TWDS impact on forest cover is currently implemented in the VEGA-Science system as a part of "IKI-Monitoring" CCU. The web-interface of TWDS SRMV is shown in Figure 1.

In order to fulfill the requirements for automatic detection of the TWDS impact on forest vegetation cover (see Sec.4) the following upgrades have been added to VEGA-Science system:

1) the TWDS database,

2) automatic and semi-automatic software for management of pairs "controlled forest plot" - "reference forest plot",

3) DB of taxonomically homogeneous forest areas,

4) DB of homogeneous weather and climatic zones according to long-term hydrometeorological observations,

5) DB of seasonal phenological profiles (see profile panels in Figure1) of observed satellite monitoring data and derived data products for selected forest plots,

6) software for estimation of decadal, monthly and seasonal average values of spectral indices based on long-term satellite monitoring of the forest plots polygon network.

In addition, the ObjectsSurveysSMIS tool of VEGA-Science system was upgraded to meet the functional requirements listed in Sec.5. As part of this task, a methodology has been developed to determine the degradation of forest vegetation based on a comparison of a homogeneous forest in polluted and nonpolluted areas, i.e. for plots with TWDS impact compared to the ones without impact. For these purposes, several types of TWDS control plots were established in the neighboring area of controlled or monitored TWDS: dump sites and embankments, "polluted" and "unpolluted" forest plots, which are polygons down and up along the prevailing wind directions from the TWDS. So, TWDS SRMV consists of a database of the objects, a library of access to it, a processing system and tools that allow working with objects, controlling the processing of satellite data and analyzing the dynamics of changes in objects in web-based interface (see General functional scheme in Figure 2).

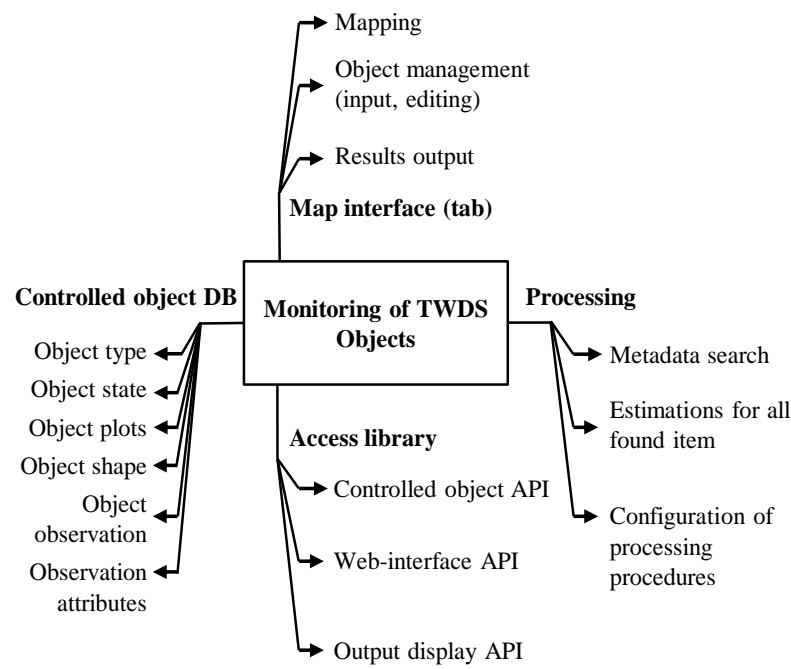

Figure 2. General functional scheme of TWDS SRMV

Submitting the contour of a TWDS object can be performed using the VEGA-Science polygon editing tool (Figure 3). The selection of contaminated plots is made in accordance to the wind rose down in the prevailing wind directions. For example, if the prevailing wind is north, then the contaminated sites are selected from the south side of the dumps. Annotation of the site by the type of vegetation prevailing in it is carried out automatically. However, the operator must ensure the final selection (Figure 4) of both uncontaminated and contaminated forest sites so that they have the same (or close to each other) taxonomy.

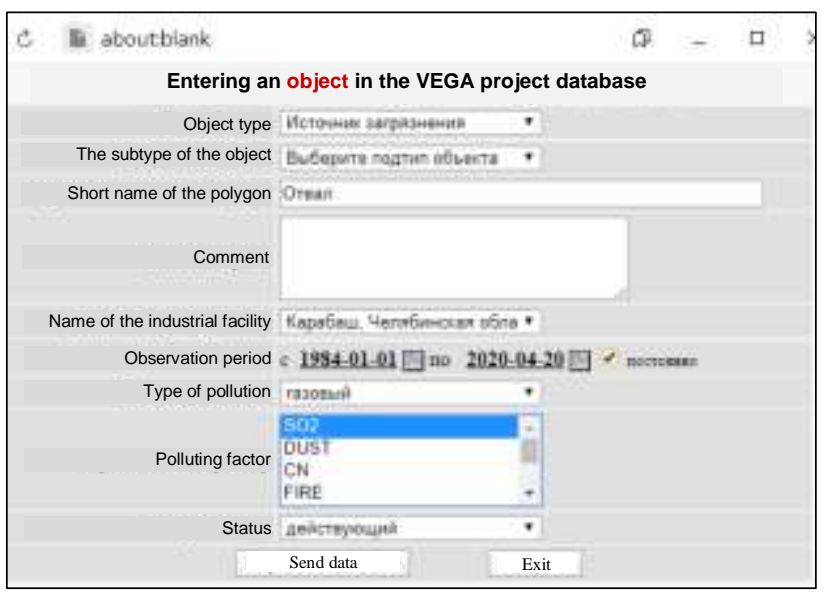

Figure 3. Registration of TWDS

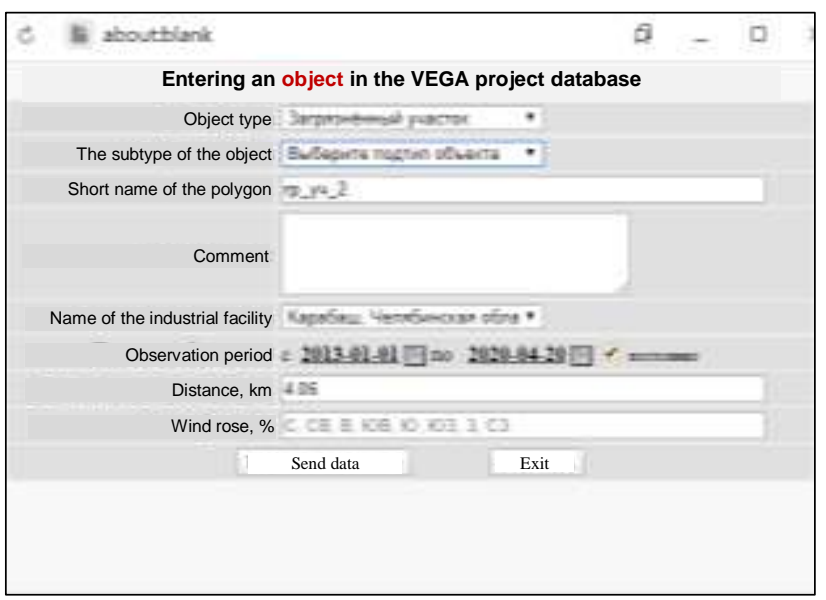

Figure 4. Registration of TWDS control plots

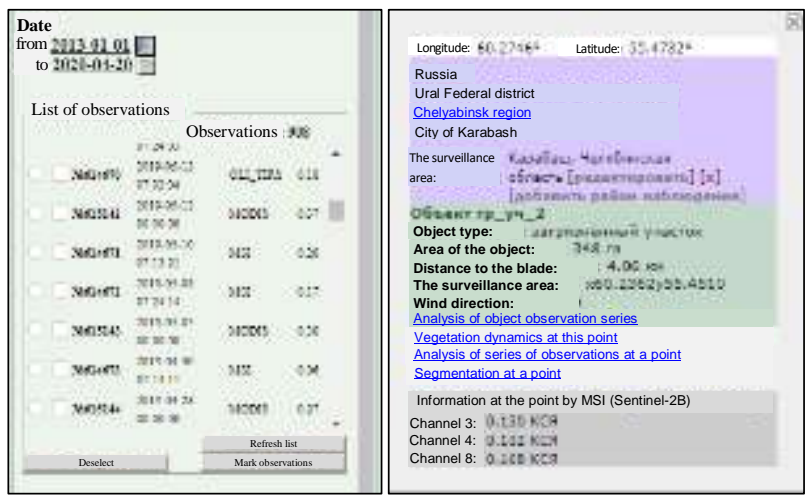

Figure 5. Output monitoring panel

In automatic mode, statistical characteristics of remotely observed data, their spectral indices, and retrieved products are estimated for previously selected forest plots. As characteristics of the observations, we take the values in various spectral channels and the values of multichannel spectral indices, including NDVI, PVI, etc. (see Table 2). All indices mentioned in Table 2 are ASTER band numbers: $10-8.125-8.475 \mu \mathrm{m}$, 
11- 8.475-8.825 $\mu \mathrm{m}, 12-8.925-9.275 \mu \mathrm{m}, 13-10.25-10.95 \mu \mathrm{m}$, $14-10.95-11.65 \mu \mathrm{m}$. (Gornyy, 2008).

\begin{tabular}{|c|c|}
\hline Space platform & TERRA, AQUA, SENTINEL \\
\hline Scientific Instrument & MODIS, VIIRS, etc. \\
\hline ID & $\begin{array}{c}\text { Controlled object ID } \\
\text { (aothomatic input) }\end{array}$ \\
\hline Mean reflectance & $\begin{array}{c}\text { Mean reflectance value per } \\
\text { channel }\end{array}$ \\
\hline $\begin{array}{c}\text { Standard deviation of } \\
\text { reflectance }\end{array}$ & $\begin{array}{c}\text { Standard deviation of } \\
\text { reflectance value per channel }\end{array}$ \\
\hline NDVI & Mean value of NDVI \\
\hline $\begin{array}{c}\text { Standard deviation of } \\
\text { NDVI }\end{array}$ & Standard deviation of NDVI \\
\hline PVI & Mean value of PVI \\
\hline $\begin{array}{c}\text { Standard deviation of } \\
\text { PVI }\end{array}$ & Standard deviation of PVI \\
\hline Disturbancy index & Mean value of TIED \\
\hline $\begin{array}{c}\text { Standard deviation of } \\
\text { disturbancy index }\end{array}$ & Standard deviation of TIED \\
\hline $\begin{array}{c}\text { Silicate index (bare } \\
\text { land) }\end{array}$ & $I_{\left[S i O_{4}\right]^{4-}}=\frac{\varepsilon_{14}}{\varepsilon_{12}}$ \\
\hline $\begin{array}{c}\text { Carbonate index (bare } \\
\text { land) }\end{array}$ & $I_{\left[\mathrm{CO}_{3}\right]^{2-}}=\frac{\varepsilon_{12}}{\varepsilon_{14}}$ \\
\hline $\begin{array}{c}\text { Sulphate index (bare } \\
\text { land) }\end{array}$ & $I_{\left[S O_{4}\right]^{2-}}=\frac{\varepsilon_{12}}{\varepsilon_{11}}$ \\
\hline $\begin{array}{c}\text { Native sulfur index } \\
\text { (bare land) }\end{array}$ & $\begin{array}{c}I_{[S]}=\frac{\left(\varepsilon_{14}-\varepsilon_{12}\right)\left(\varepsilon_{12}-\varepsilon_{10}\right)}{\varepsilon_{10}} \\
\text { if }\left(\varepsilon_{14}-\varepsilon_{12}-\varepsilon_{10}\right)<0, \text { then } I_{[S]}=0\end{array}$ \\
\hline
\end{tabular}

Table 2. Attributes of control products for space monitoring of the TWDS impact on surrounding vegetation

The generated series of observations can be marked by the user for high-quality and incorrect observations with subsequent export in tabular format (xls). The series of data can by studied with analytic module providing automatic charting, which provides the opportunity to analyse the seasonal, annual and long-term dynamics of changes in objects (see Figure 6).
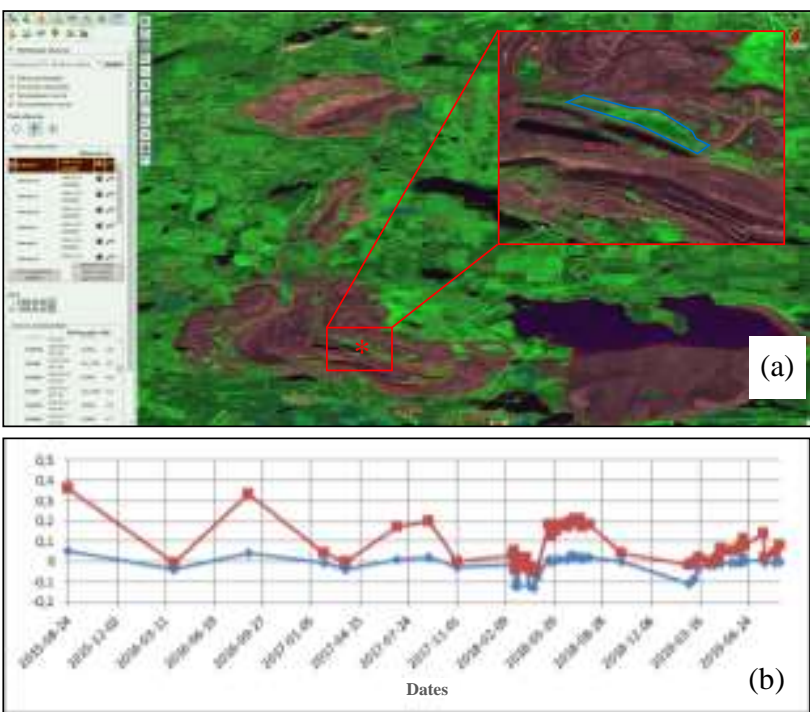

Figure 6. TWDS impact area (a) and multiyear profile (b) of monitored data for given control plot (marked by * sign on (a) panel). Red - NDVI, blue - PVI

\section{CONCLUSIONS}

Proposals for the modernization and improvement of VEGAScience services, which are necessary for the organization and analysis of long-term variability of vegetation caused by the influence of TWDS, are formulated. In order to test the feasibility of the proposal implementation, a working software prototype of the specialized unit for remote monitoring of vegetation cover in the TWDS regions was created as a part of the VEGA-Science system. Namely, all requested services were implemented in the automated system for remote monitoring of vegetation cover (SRMV) VEGA-Science services system.

\section{ACKNOWLEDGEMENTS}

The study was supported by RFBR in framework of the scientific project No. 18-29-24121 MK using resources of the IKIMonitoring Center (Loupian et al., 2015, Loupian et al., 2019).

\section{REFERENCES}

Bartalev, S.A., Egorov, V.A., Zharko, V.O., Loupian, E.A., Plotnikov, D.E., Khvostikov, S.A., Shabanov, N.V., 2016. Land cover mapping over Russia using Earth observation data, Moscow: IKI RAN.

Gornyy, V.I., 2008. Development of technologies for monitoring and forecasting the state of the land based on remote sensing data (RSD), the formation of information resources SDMZ APK [System for remote monitoring of agricultural land], Scientific report, Stage 2. St. Petersburg Research Center for Environmental Safety, Russia.

Gornyy, V.I., Kritsuk, S.G., Latypov, I.Sh., 2010. Remote mapping of thermodynamic index of ecosystem health disturbance. Journal of Environmental Protection, 1, 242-250.

Gornyy, V.I., Kritsuk, S.G., Latypov, I.Sh., 2011. Thermodynamic approach for remote mapping of ecosystem disturbance. Sovremennye problemy distantsionnogo zondirovaniya Zemli iz kosmosa, 8(2), 179-194.

Gornyy, V.I., Kritsuk, S.G., Latypov, I.Sh., Khramtsov, V.N., 2013. Verification of large scale maps of thermodynamic index ecosystem health disturbance. Sovremennye problemy distantsionnogo zondirovaniya Zemli iz kosmosa, 10(4), 201-212.

Gornyy, V.I., Kiselev, A.V., Kritsuk, S.G., Latypov, I.Sh., Tronin, A.A., 2019. Thermodynamic approach to satellite mapping of accumulated ecological losses of forest ecosystems. Sovremennye problemy distantsionnogo zondirovaniya Zemli iz kosmosa, 16(4), 124-136. doi: 10.21046/2070-7401-201916-4-124-136.

Jorgensen, J.S., Svirezhev, Yu.M., 2004. Towards a Thermodynamic Theory for Ecological Systems. Oxford: Elsever.

Kalabin, G.V., Gornyy, V.I., Davidan, T.A., Kritsuk, S.G., Tronin, A.A., 2018. The response of the tundra ecosystem to the removal of anthropogenic load from the Valkumey mine. Fiziko-tekhnicheskie problemy razrabotki poleznykh iskopaemykh, 2, 146-153.

Kashnitskii, A.V., Loupian, E.A., Balashov, I.V., Konstantinova, A.V., 2016. Technology for designing tools for the process and analysis of data from very large scale distributed satellite archives. Optika atmosfery i okeana, 29(9), 772-777. 
Kaznina, N.M., Titov, A.F., Topchieva, L.V., Laidinen, G.F., Batova, Yu.V., 2012. The effect of age-related differences on the reaction of barley plants on the action of cadmium. Fiziologiya rastenii, 59(1), 74-79.

Kositsin, A.V., Alekseeva-Popova, N.V., 1983. The effect of heavy metals on plants and mechanisms of metal resistance. Rasteniya $v$ ekstremal'nykh usloviyakh mineral'nogo pitaniya, Leningrad: Nauka, 5-22.

Kritsuk, S.G., Gornyy, V.I., Latypov, I.Sh., 2016. Spatial resolution improvement of satellite mapping of thermal properties of land surface. Sovremennye problemy distantsionnogo zondirovaniya Zemli iz kosmosa, 13(5), 277290. doi: 10.21046/2070-7401-2016-13-5-277-290.

Krupa, S.G., Arndt, U., Dempster, J.P., Manning, W.J., 1990. (eds) The Hohenheim long-term experiment: Effects of ozone, sulphur dioxide and simulated acidic precipitation on Tree Species in a Microcosm, Elsevier, 68(3-4), 93-478.

Loupian, E.A., Savorskiy, V.P., Shokin, Yu.I., Aleksanin, A.I., Nazirov, R.R., Nedoluzhko, I.V., Panova, O.Yu., 2012. Up-todate approaches and technology arrangement of Earth observation data applications aimed to solve scientific tasks. Sovremennye problemy distantsionnogo zondirovaniya Zemli iz kosmosa, 9(5), 21-44.

Loupian, E.A., Proshin, A.A., Burtsev, M.A., Balashov, I.V., Bartalev, S.A., Efremov, V.Yu., Kashnitskiy, A.V., Mazurov, A.A., Matveev, A.M., Sudneva, O.A., Sychugov, I.G., Tolpin, V.A., Uvarov, I.A., 2015. IKI center for collective use of satellite data archiving, processing and analysis systems aimed at solving the problems of environmental study and monitoring. Sovremennye problemy distantsionnogo zondirovaniya Zemli iz kosmosa, 12(5), 263-284.

Loupian, E.A., Proshin, A.A., Bourtsev, M.A., Kashnitskii, A.V., Balashov, I.V., Bartalev, S.A., Konstantinova, A.M., Kobets, D.A., Mazurov, A.A., Marchenkov, V.V., Matveev, A.M., Radchenko, M.V., Sychugov, I.G., Tolpin, V.A., Uvarov, I.A., 2019. Experience of development and operation of the IKI-Monitoring center for collective use of systems for archiving, processing and analyzing satellite data. Sovremennye problemy distantsionnogo zondirovaniya Zemli iz kosmosa, 16(3), 151-170. doi: 10.21046/2070-7401-2019-16-3-151-170.

Richards, J.A., Jia, X., 2006. Remote Sensing Digital Image Analysis. Berlin Heidelberg: Springer.

Savorskiy, V.P., Kashnitskii, A.V., Konstantinova, A.M., Balashov, I.V., Krasheninnikova, Yu.S., Tolpin, V.A., Maklakov, S.M., Savchenko, E.V., 2016. Capabilities of hyperspectral indices analysis of the Vega-Constellation remote monitoring information systems. Sovremennye problemy distantsionnogo zondirovaniya Zemli iz kosmosa, .13(3), 28-45. doi: 10.21046/2070-7401-2016-13-3-28-45.

Savorskiy, V.P., Panova, O.Yu., Savchenko, E.V., 2018. Methods for analyzing satellite monitoring data on plant areals to identify illegal crop fields in the conduct of special examinations. Sovremennye problemy distantsionnogo zondirovaniya Zemli iz kosmosa, 15(5), 13-30. doi: 10.21046/2070-7401-2018-15-5-13-30.

Savorskiy, V.P., Loupian, E.A., Gornyy, V.I., Ermakov, D.M., Panova, O.Yu., Konstantinova A.V., 2019. Methods and information tools for analyzing remote sensing data to detect changes in vegetation caused by industrial waste and dumps. Sovremennye problemy distantsionnogo zondirovaniya Zemli iz kosmosa, 16(6), 31-47. doi: 10.21046/2070-7401-2019-166-31-47.

Schweizer, B., Arndt, U., 1990. $\mathrm{CO}_{2} \mathrm{H}_{2} \mathrm{O}$ gas exchange parameters of one and two year old needles of spruce and fir. Environmental pollution, 68, 275-292.

Scientific report, 2008. Stage 2. Development of technologies for monitoring and forecasting the state of the land based on remote sensing data (RSD), the formation of information resources SDMZ APK [System for remote monitoring of agricultural land], V.I. Gornyy. St. Petersburg Research Center for Environmental Safety.

Seregin, I.V., Ivanov, V.B. 2001. Physiological aspects of the toxic effects of cadmium and lead on higher plants. Fiziologiya rastenii, 48(4), 606-630.

Slonecker, T., Fisher, G.B., Aiello, D.P., Haack, B., 2010. Visible and Infrared Remote Imaging of Hazardous Waste: A Review. Remote Sensing, 2(11), 2474-2508. doi:10.3390/rs2112474.

Titov, A.F., Kaznina, N.M., Talanova, V.V., 2014. Plant resistance to heavy metals. Petrozavodsk: Karel'skii nauchnyi tsentr RAN.

Tolpin, V.A., Loupian, E.A., Bartalev, S.A., Plotnikov, D.E., Matveev, A.M., 2014. Possibilities of agricultural vegetation condition analysis with the "VEGA" satellite service. Optika atmosfery i okeana, 27(7), 581-586.

Van der Meer, F.D., de Long, S.M., 2006. Imaging spectrometry. Neederland: Springer.

Wang, J.Xu, R., Ma, Y., Miao, L., Cai, R., Chen, Yu., 2008. The research of air pollution based on spectral features in leaf surface of Ficus microcarpa in Guangzhou, China. Environmental Monitoring and Assessment, 42, 73-83. doi: 10.1007/s10661007-9909-6.

Zakharov, A.I., Savorskiy, V.P., Zakharova, L.N., 2018. Investigation of the influence of weather phenomena on radar images of vegetation of the Moscow region. Abstract of 16th AllRussian open conference "Modern problems of remote sensing of the Earth from space", November 12-16, 2018, IKI RAS, Moscow, 407. 